\title{
An Empirical Analysis on the Monopoly of Designated Health-Care Institutions in China's New-type Rural Cooperative Medical System
}

\author{
Shiwen Zeng \\ School of Economics, Southwestern University of Finance and Economics \\ Chengdu 610074, China \\ E-mail: 1xin111107@sina.com \\ Yang Hao \\ School of Economics, Southwestern University of Finance and Economics \\ Chengdu 610074, China
}

\begin{abstract}
In accordance with the monopoly of designated health-care institutions in China's New-type Rural Cooperative Medical System, this article aims at establishing a model to reveal the manifestations of monopoly and its damage to peasants' benefits based on the statistics and empirical analysis on the data obtained from on-the-spot investigations as well as some indexes from relevant documents. It ends with some improvement plans to lessen or even smash up the monopoly of designated health-care institutions in Chinas' present situation in order that both peasants and the whole Chinese society could benefit more.
\end{abstract}

Keywords: New-type Rural Cooperative Medical System (CMS), Monopoly, Medicine monopoly, Service monopoly, Lerner index

\section{Introduction}

The fundamental starting point of China's New-type Rural Cooperative Medical System can be summed up by a saying popular with people in China which reads "China's New-type Rural Cooperative Medical System provides a guarantee for people's health in which any person suffering from a disease will be helped by others as well as the government". As a result, this policy has settled the problem of poverty caused by peasants' diseases. However, monopoly of designated health-care institutions is increasingly apparent, due to which (a twofold monopoly: patients-health-care institutions-medicine and services) peasants' benefit from CMS has been affected, so has CMS's social profit. Originating from Mencius' works, "monopoly", in capitalist economy, refers to a union formed by a handful of big enterprises to earn high profit by controlling the production, sales and prices of one or several commodities. Chinese designated health-care institutions' dominance over the sales process and prices of medicine forms what we call "monopoly".

As an old saying goes, a nation will not stay stable without agriculture, will not prosper without industry and will not flourish without commerce. What is the purpose of China's economic construction if the health of peasants, who has $63.91 \%$ of China's total population, isn't attached importance to and gets improved? Written in the period of laying down medical reform policies, this article is of particular practical significance, with which we hope to make a contribution for the current medical reform.

\section{Literature Review}

Ever since its birth, CMS has undergone a lengthy period for development and improvement. However, when treated in designated health-care institutions, peasants are apparently struck by: the rising prices of drugs, prescribing unnecessary expensive drugs or drugs excluded from CMS medicare formulary which cannot be reimbursed, forcing patients with minor diseases to be hospitalized or even listing it as a precondition for reimbursement, an increasing number and variety of physical test items, the deteriorating service quality and attitudes delivered by the medical and nursing staff. It is these monopolistic behaviors of designated health-care institutions that have resulted in the damage to peasants' benefit. 
As for how to lessen or even smash up monopoly, Fumin Sui and Feng Han think it essential for the improvement of the current asymmetrical information between doctors and patients to increase peasants' knowledge in health care (Sui, Han, 2008). According to Yanyan An and Biao Luo, to establish an access competitive sytem, to improve peasants' organizing and negotiating abilities as well as to transform the government's role and to perfect public health policies are three measures to get rid of the monopoly existing at county health-care markets. (An, Luo, 2007) All of these are good suggestions. Nevertheless, in the present studies on China's CMS, many experts mainly focus their attention to the perfection of CMS system (Chen, 2005), capital raising (Cai, Hao, 2005) and the participation rate in CMS (Li, 2008), leaving the monopoly of designated health-care institutions and relevant empirical analyses untouched. Actually, during the implementation of CMS, monopoly harasses the further development of the whole system to some degree. Only when they are settled will CMS be put into better effect.

When measuring the degree of monopoly or market power, different measurement indexes should be selected in accordance with different market structures and product homogeneity.

(1) Lerner Index: it is created by Abba Ptachya Lerner to measure the deviation degree of price from marginal cost, which can be applied to a monopolized market with simple structure and product homogeneity. The formula is as follows:

$$
\mathrm{LI}=1 /|\mathrm{e}|=(\mathrm{p}-\mathrm{MC}) / \mathrm{p}
$$

In this formula, $|\mathrm{e}|$ refers to the price elasticity of demand, which is equal to $-(\mathrm{dq} / \mathrm{dp}) \cdot(\mathrm{p} / \mathrm{q})$. Here, $\mathrm{p}$ is the market price and $\mathrm{MC}$ is the marginal cost of commodities.

(2) The generalized form of Lerner Index is fit for a monopolized market with complex structure and product homogeneity, which is expressed as:

$$
\mathrm{mi}=(\mathrm{p}-\mathrm{MC}) / \mathrm{p}=(\mathrm{a} / \mathrm{e})+[(1-\mathrm{a}) / \mathrm{e}] \mathrm{si}
$$

Supposing there are $\mathrm{n}$ manufacturers at market, $|\mathrm{e}|$ is the price elasticity of demand, which is equal to $-(\mathrm{dq} / \mathrm{dp}) \cdot(\mathrm{p} / \mathrm{q})$. Here, $\mathrm{p}$ is the market price, $\mathrm{MC}$ is the marginal cost of commodities and si refers to the market share of the $\mathrm{i}^{\text {th }}$ manufacturer.

(3) Surplus demand method: it is fit for a market with complex structure and without product homogeneity, taking every manufacturer's surplus demand function as well as the relations between the measurement profit rate and the monopoly power.

\section{Current Implementation of CMS}

By the end of 2008, China's total participation rate in CMS had been over $80 \%$. In addition, the two-year period has improved the capital raising ability to 100 yuan.

As is revealed in our questionnaires, designated health-care institutions have formed market monopoly since all of them are owned by the government instead of a variety of economies, hence lacking in market competition. In addition, high medicine prices and inferior services are also harassing their development. These problems are summed up in two kinds of monopoly.

Medicine monopoly: rising prices, larger amount of doses, prescribing more kinds of drugs, expensive drugs or drugs not included in the medicare formulary.

Service monopoly: increasing test items or analysis items, forcing those patients with minor diseases to be hospitalized and a cool manner of service.

\section{Empirical Analysis}

By accumulating, arranging and analyzing relevant documents, we focus our attention on investigating, from the perspectives of index selection as well as model establishment, the monopoly of designated health-care institutions in drugs and services.

\subsection{Index-Lerner Index}

This index serves as an important measurement for market monopoly degree and market power, which is expressed in the following formula:

$$
\mathrm{LI}=1 /|\mathrm{e}|=(\mathrm{p}-\mathrm{MC}) / \mathrm{p}
$$

In this formula, $|\mathrm{e}|$ is the price elasticity of demand, which is equal to $-(\mathrm{dq} / \mathrm{dp}) \cdot(\mathrm{p} / \mathrm{q})$. Here, $\mathrm{p}$ is the market price and MC is the marginal cost of commodities.

(1) Supposing the market has a completely monopolized structure, we can get the price elasticity of demand with the given profit function starting with the profit-maximization goal of monopoly manufacturers. China's designated health-care market is divided into three levels: the county level, the district level and the city level. Due to the basically 
same treatments peasants receive at the markets at different levels, it is safe to say that it is a completely monopolized market.

(2) Supposing the monopoly market has product homogeneity, with an exception of the different products provided in outpatient treatment and hospitalization treatment, it is safe to say that different products provided by the markets at different levels can replace each other totally in function. Here, in order to get the value of $|\mathrm{e}|$, we have to set up a model of market price and demand

$$
\operatorname{Ln} q=a+b \operatorname{Ln} p+u
$$

In this model, $p$ is the average price of the products provided at any outpatient market or hospitalization market, that is, the average price of an outpatient or hospitalization treatment at designated health-care institutions; $q$ is the average price of the treatment peasants are willing to accept. By differentiating the two ends of the above model, we arrive at the result $\mathrm{b}=(\mathrm{dq} / \mathrm{dp}) \cdot(\mathrm{p} / \mathrm{q})$, which is $|\mathrm{e}|$.

\subsection{Model}

Here, a model is employed to investigate the relations among medicine monopoly, service monopoly, per capita living expenditure and its monopoly degree (manifested by Lerner Index)

$$
L I=\alpha_{0}+\alpha_{1} M E D M O N O+\alpha_{2} S E R M O N O+\alpha_{3} \operatorname{Ln}(E X P P E R)+u
$$

In this model, LI refers to Lerner Index, MEDMONO to medicine monopoly, SERMONO to service monopoly, EXPPER to expenditure per person.

The source of data:

LI is obtained by establishing the above model;

MEDMONO is obtained from the average difference between the prices of medicine before and after participating in CMS, that is,

MEDMONO $=($ the medicine price before participating in CMS- the medicine price after participating in CMS)/n $(\mathrm{n}$ refers to the valid number of interviewed peasants participating in CMS)

SERMONO comes from the data in questionnaires, that is, the evaluation given by peasants participating in CMS on the services of designated health-care institutions, ranging from 1 to 10 points.

EXPPER, coming from questionnaires, is mainly employed to give great convenience to our investigation as well as to show the normality of our analysis.

\subsection{Result}

(1) by processing the data we have got as well as assessing the model with STATA, we finally reach the

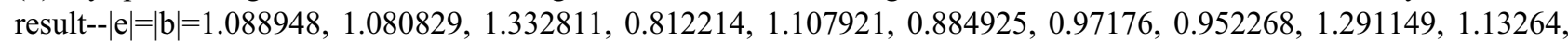
which means that the prices of products provided by designated health-care institutions exceed the marginal cost by $108.8948 \%, 108.0829 \%, 133.2811 \%, 81.2214 \%, 110.7921 \%, 88.4925 \%, 97.176 \%, \quad 95.2268 \%, 129.1149 \%, 113.264 \%$ respectively.

(2) based on the value of Lerner Index got from (1) and the data from other investigations, we have an assessment of model with the help of STATA

$$
\mathrm{LI}=1.180665-.0358 \mathrm{MEDMONO}-.0275 \mathrm{SERMONO}+.0471 \mathrm{Ln}(\mathrm{EXPPER})
$$

$$
\text { (2.9121) }
$$

The following conclusions can be reached from the above model:

a. the difference between the medicine prices before and after participating in CMS has an increase of one unit (supposing the medicine price before participating CMS remains unchanged, the one-unit increase in price difference means the decrease of one unit in medicine price after participating in CMS) and Lerner Index is reduced by 0.0358 unit (a $3.58 \%$ decrease in the degree of monopoly);

b. service marks are improved by 1 point and the degree of monopoly is reduced by $0.0275(2.75 \%)$;

c. the expenditure per person is improved by $1 \%$ and the degree of monopoly is increased by $4.71 \%$. It shows that, with peasants' higher average expenditure, the degree of monopoly in designated health-care institutions is increased accordingly, so is the degree of monopoly peasants with higher per capita expenditure have to face when treated in designated health-care institutions.

\subsection{Causes for Monopoly}

(1) the great variety of designated health-care institutions and the lack of a competition system have led to a decline in the service quality of designated health-care institutions. 
(2) it has caused the medical staff's pursuit for quantity instead of quality when treating patients to integrate their wages and bonuses with the incomes of hospitals.

\section{Countermeasure Suggestions}

\subsection{Increasing Peasants' Knowledge in Health Care}

Due to the "externality" of public health, the policy of putting precaution first should be implemented fully in rural health-care field, that is to say, great efforts should be made to promote the construction of rural public health system. Currently, the increased medicine prices, unnecessary expensive medicine and a variety of test items have resulted in peasants' higher expenditure in medicine. However, only a tiny slice can be reimbursed. Therefore, it will help peasants to prevent themselves from having some diseases as well as to cut down their expenditure in medicine to increase their knowledge in health care.

\subsection{Establishing Access Competitive Medical System}

As for the establishment of access competitive medical system, peasants are not concerned about whether health-care institutions are designated or not, but lower expenditure in their medical treatment resulting from competition. Taking the poor service attitudes and quality as well as the higher medical expenses into consideration, we should introduce a competition system, in which the ownership of health-care institutions should be paid attention to to guarantee fair competition among health-care institutions of different natures. Accordingly, public health institutions are responsible for public health duties. Efforts can be made in the following two aspects:

(1) introducing competition among designated health-care institutions, only through which any institution will gain the priority as a designated one. Meanwhile, qualification standards for CMS designated health-care institutions should be established to assess the qualification of the existing ones. Only passing the assessment will an institution win the honorary title of "CMS Designated Health-care Institutions"

(2) introducing competition between designated health-care institutions and other medical treatment suppliers to give the latter a chance for survival. The qualification standards mentioned above also apply to the assessment of other medical treatment suppliers, through which those excellent ones will win honorary titles such as "Trustworthy Units" or "Excellent Units" and so on.

\subsection{Strengthening Medical Staff's Moral Construction}

When strengthening medical staff's moral construction, assessment standards for medical staff's wages and bonuses should be based on the result of treatment.

There is one point that distinguishes the health-care market and the ordinary market, which is adverse selection and moral risk. Due to patients' complete ignorance of medicine, doctors tend to give big prescriptions. In addition, the insurance system of CMS makes these big prescriptions be implemented. In such a situation, moral construction is not only essential but to be strengthened. However, the current system in which doctors' incomes are related to hospital incomes should be broken up by conducting a management system separating incomes from expenses. In addition to that, the medical staff is expected to have skills as well as kindness to solve the difficulties of patients effectively. Accordingly, their wages and bonuses should not be based on the incomes they create for their hospitals, but on the result of their treatment on patients.

\section{References}

(1980). Sherman Act. (Trade and Business Act on Resisting Illegal Restrictions and Monopoly Protection)

(2005). Peasants in Linyi of Shandong Province don't have to go to Designated Health-care Institutions. [Online] Available: http://www.xinhuanet.com/(Retrieved from December 7)

An, Yanyan. Luo, Biao. (2007). Research on China's County and Countryside Medical Monopoly Equilibrium and Countermeasure to Break It. Journal of Guangxi Economic Management Cadre College, Vol. 2.

Cai, Lin, Luo, Li, Pan, Yingbing, Li, Chunfang, Cui, Xin, Song, Mingshan, Chen, Zheng \& Chen, Jiansheng. (2005). The Design and Improvement of New-type Rural Collective Medical Fund-raising System. Finance and Economics, Vol.1.

Chen, Yongjun \& Hu, Debao. (2008). An Analysis on China's Telecom Industry: An Empirical Analysis Based on Surplus Demand. Guangxi Social Science, Vol. 8.

Chen, Zhiguang. (2004). Monopoly or Efficiency: An Empirical Study on China's Manufacturing Industry. Management World, Vol.12.

China National Bureau of Statistics. (2008). Yearbook of Statistics of Sichuan in 2008.

Du, Yun \& Zhang, Minghong. (2007). A Disquisition on the Theory of Public Regulation and Anti-monopoly Based on Experimental Economics. Journal of Finance and Economics, Vol.7. 
Gao, Hongwen \& Yang, Hong. (2007). An Empirical Study on the Existence of Monopoly in China's Real Estate Market. Modern Business, Vol.13.

Gao, Hongye. (2001). Western Economics. Beijing: China Renmin University Press.

Li, Weiping, Shi, Guang \& Zhao, Kun. (2003). History, Current Situation and Problems of China's Rural Health Care. Management World, Vol. 4.

Li, Xiangyun. (2008). Investigation and Reflections on the Participation Rate in CMS in Beijing. Southern Rural, Vol.1. Luo, Jiahong, Mao, Yong, Li, Xiaomei, Che, Gang, He, Liping, Yu, Jian, Cao, Quanke, Qiu, Hongzhong \&Yuan, Jie. (2005). Modern Health Economics. Science Press.

Wen, Tiejun. (2001). Breaking the Monopoly in Rural Economy: 800-million Peasants'Fates. China Reform, Vol. 8.

Sichuan Health Department. (2007). Medicare Formulary of New-type Rural Cooperative Medical System in Sichuan (revised).

Yin, Qie. (2005). Appraisement of Participating Farmers on the Service Quality of Designated Medical Institutions of New-type Rural Cooperative Medical System. Chinese Journal of Hospital Statistics, Vol. 4.

Zhang, Liming, Wang, Dong \& Hao, Mo. (2005). On the Sustainability of Fund Raising for New-type Rural Collective Medical Care. Chinese Health Resources, Vol. 6.

Zhao, Binfeng. (2008). Sichuan Rural Daily.

World Health Organization. (1983). Primary Health Care: the Chinese Experience. 